TITLE:

\title{
Effects of the physical characteristics of seeds on gastrointestinal passage time in captive Japanese macaques
}

\author{
AUTHOR(S): \\ Tsuji, Y.; Morimoto, M.; Matsubayashi, K.
}

\section{CITATION:}

Tsuji, Y.... [et al]. Effects of the physical characteristics of seeds on gastrointestinal passage time in captive Japanese macaques. Journal of Zoology 2009, 280(2): 171-176

\section{ISSUE DATE:}

2009-10-27

URL:

http://hdl.handle.net/2433/197180

\section{RIGHT:}

This is the peer reviewed version of the following article: Tsuij, Y., Morimoto, M. and Matsubayashi, K. (2010), Effects of the physical characteristics of seeds on gastrointestinal passage time in captive Japanese macaques. Journal of Zoology, 280: 171-176, which has been published in final form at http://dx.doi.org/10.3106/041.036.0308; この論文は著 者最終稿です。内容が印刷版と異なることがありますので、引用の際には出版社版をご確認ご利用ください。This is the Accepted Author Manuscript. Please cite only the published version. 
1 Effects of the physical characteristics of seeds on gastrointestinal passage time in

2 captive Japanese macaques

3

4 Yamato Tsuji, Mayumi Morimoto, and Kiyoaki Matsubayashi

$5 \quad$ Primate Research Institute, Kyoto University

6

7 Short title: Seed characteristics and passage time of Japanese macaques

8

9 *Correspondence should be addressed to: Yamato Tsuji, Primate Research Institute,

10 Kyoto University

11 Address: 484-8506, 42-2, Kanrin, Inuyama City, Aichi Prefecture, Japan.

12 E-mail: ytsuji@ pri.kyoto-u.ac.jp

13 Tel / Fax: +81-568-63-0539 
Tsuji et al. 2

\section{Abstract}

15 The time it takes seeds to pass through the gut of vertebrates is an important aspect of 16 endozoochorous seed dispersal because it influences seed dispersal distance. The

17 physical characteristics of seeds (e.g., dry seed weight, volume, and specific gravity) vary 18 among plant species, which might cause a difference in seed movement through the

19 gastrointestinal system. We conducted feeding experiments with captive female Japanese

20 macaques (Macaca fuscata) $(\mathrm{n}=5)$ using eight different types of seeds to evaluate the

21 effects of the physical characteristics of seeds on their passage time. Median seed

22 recovery percentage for the real seeds was $35.5 \%$ (range, 24\%-78 \%). Among three

23 passage time variables examined, mean retention time (MRT) (37-54 hr) and time of last

24 appearance of a seed (TLA) (53-109 hr) differed significantly among seed types, and the

25 latter differed significantly among individuals. Transit time (TT) $(22-35 \mathrm{hr})$ did not. The

26 generalized linear models (GLM) selected dry seed weight as the most important factor

27 affecting $M R T$, while specific gravity of seeds as the most important factor affecting TLA.

28 This implies that 1) heavier seeds and (or) seeds with greater specific gravity remain in

29 the gut longer and are likely to be dispersed farther from the parent plant, and 2) the

30 lighter seeds and (or) seeds with lower specific gravity are dispersed nearer the parent.

31 Our study demonstrated the importance of considering the effects of the physical 
32 characteristics of seeds on the manner which primates disperse plant species, though we

33 should consider the effect of the individual variation in the passage time, too.

35 Key words: Japanese macaque, passage time, seed dispersal, seed size, specific gravity 
Tsuji et al. 4

36

37

38

39

40

41

42

43

44

45

46

47

48

49

50

51

52

53

\section{Introduction}

Endozoochory is the dispersal of seeds that pass unharmed through digestive tracts of animals. According to Pollux et al. (2007), endozoochory depends on the following four stages: 1) the probability that seeds are ingested by animals;2) the time of seed retention in the digestive system (i.e., passage time); 3) the resistance of seeds to digestion, and 4) the viability and germination rate of seeds after passage through the gut.

Among these factors, passage time influences the dispersal distance of seeds (Link \& Di Fiore, 2006). In several plant species, seeds moved further away from the parent plants have a greater chance of survival (Garber, 1986), though this may not be the case for all plant species and (or) every season (Augspurger, 1984; Chapman \& Chapman, 1996). To date, the retention time of seeds in the primate gut has been studied particularly through feeding experiments using particle markers that imitate real seeds (e.g., Dierenfeld, Koontz \& Goldstein, 1992; Maisels, 1993) and on a few occasions by direct observation of wild primates (Garber, 1986; Julliot, 1996).

There are numerous variables which should affect the passage time: time of day, health / age / sex of the animal, stress, quantity / quality of foods, etc. Among these factors, our focus in this study is on the physical characteristics of seeds (e.g., seed size, shape, coat hardness, and external structure). The physical characteristics of seeds differ 
Tsuji et al. 5

54 among plant species. These variations in seed characteristics may have an important

55 influence on the passage time in the gut of animal dispersers (Traveset, 1998). For

56 example, Leavy \& Grajal (1991) and Schwarm et al. (2008) showed negative correlations

57 between seed size ( $\mathrm{mm}$ ) and passage time in cedar waxwings Bombycilla cedrorum and

58 the pygmy hippopotamus Hexaprotodon liberiensis, respectively. In such cases, smaller

59 seeds would be dispersed farther from parent plants. In contrast, Julliot (1996), Wotton,

60 Clout \& Kelly (2008), and Schwarm et al. (2008) provided evidence of a positive

61 correlation between seed size and passage time in red howler monkeys Alouatta seniculus,

62 New Zealand pigeons Hemiphaga novaezeelandiae, and bantengs Bos javanicus. Finally,

63 Garber (1986) and Gardener, McIvor \& Jansen (1993) showed a negative correlation

64 between the specific gravity of seeds and the passage time for two species of tamarin

65 monkeys, Saguinus mystax and S. fuscicollis and cattle Bos taurus. Other studies have

66 found no clear relationships between the physical characteristics of seeds and passage

67 time (emu Dromaius novaehollandiae: Wilson (1989); arctic fox Alopex lagopus: Graae,

68 Pagh \& Bruun (2004); two species of fox Pseudolopex gymnocerus and Cerdocyon thous:

69 Varela \& Bucher (2006); carp Cyprinus carpio: Pollux et al. (2007)). Thus, it appears that

70 the relationships between the physical characteristics of seeds and passage time vary

71 among animal species and may depend on difference in the size / morphology of the 
Tsuji et al. 6

72 digestive system and the digestive processes of the subject animals. Thus, this

73 relationship must be studied in individual species.

74 Primates commonly consume large amounts of fleshy fruit, and often void the intact

75 seeds while moving or during rest periods (Alouatta seniculus and Lagothrix lagotricha:

76 Yumoto, Kitamura \& Nishimura, 1999; A. guariba and Brachyteles arachnoides: Martins,

77 2006; Macaca fascicularis: Lucas \& Corlett, 1998; Papio anubis: Kunz \& Linsenmair,

78 2008a; Cercopithecus spp. and Pan troglodytes: Lambert, 2002; Gorilla gorilla: Remis,

79 2000). Differences in the ranging patterns and dietary preference of individual primate

80 species, along with physical characteristics of seeds swallowed influence their passage

81 time through the digestive system. Since primates move from several hundred meters to

82 several kilometers daily (e.g., Raemakers, 1980), a difference in passage time can result

83 in marked difference of several hundred meters in seed dispersal distance. For example,

84 Link \& Di Fiore (2006) reported that seed dispersal distances of 38 plant species averaged

$85443 \mathrm{~m}$, with about $2 \%$ of seeds retained in the gut for over 6 hours and dispersed more

86 than $1250 \mathrm{~m}$ away from the parent plant. However, few studies thus far have considered

87 the effects of the physical characteristics of seeds on primate gut passage time. A better

88 understanding of the effects of the physical characteristics of seeds on passage time is

89 necessary for evaluating the dispersal distance of seeds by primates. 
Tsuji et al. 7

90

91

92

93

94

95

96

97

98

99

100

101

102

103

104

105

106

107

In the present study we conducted feeding experiments with captive Japanese macaques (Macaca fuscata), an important seed disperser in temperate forests of Japan (Yumoto, Noma \& Maruhashi, 1998; Otani \& Shibata, 2000; Otani, 2003). We tested one prediction: passage time through the macaque gut differed based on the physical characteristics of the seeds.

Materials and methods

97 Our methodology complied with protocols approved by the guidelines (Guide for the Care and Use of Laboratory Primates, Second Edition) of the Primate Research Institute, Kyoto University, Japan, and adhered to Japan's legal requirements.

\section{Study animals and their housing conditions}

Study animals were 5 adult (>10 years) female Japanese macaques housed at the Primate Research Institute, Kyoto University, Japan (body weight: 6.7 - $10.5 \mathrm{~kg}$ ). Each animal was reared in an individual cage (W $760 \mathrm{~mm} \times \mathrm{L} 900 \mathrm{~mm} \times \mathrm{H} 850 \mathrm{~mm}$ ) in an air-conditioned $\left(20^{\circ} \mathrm{C}\right)$ experimental room. All 5 animals were active and in good condition. None were lactating or pregnant. Difference in the body weight of the monkeys before and after the experiments were not significant (paired $t$-test, $d f=4, t=1.18, P>$ 
$108 \quad 0.05)$.

109 The monkeys were fed $100 \mathrm{~g}$ of monkey chow twice a day (10:00 and 14:00). They

110 were also fed $35 \mathrm{~g}$ of sweet potatoes for morning meals three times per week. These are

111 high quality foods relative to many of the foods consumed by Japanese macaques in the

112 wild (Mori, 1979; Nakagawa et al. 1996). We alone entered the experimental room as a

113 health precaution and to minimize any stress to the animals that might affect gut retention

114 times.

115

116 Seed administration

117 Eight experimental trials were conducted from June to September 2008 (Table 1). We did

118 not change the macaques' housing conditions or diet composition during the experiments,

119 except that the sweet potatoes were replaced by chunks of banana (ca. $100 \mathrm{~g}$ ) in which we

120 inserted experimental seeds (see below). During each experiment, we continued to feed

121 the chunks of banana without seeds three times per week.

A trial consisted of providing the monkeys with nontoxic plastic seeds (two sizes of

white plastic beads) or real seeds (six types of commercial seeds) with varied dimensions

124 (Table 1). We used commercial seeds to assure similar-sized seeds. Before the experiment

125 we measured the length, width, and height of each seed $(\mathrm{n}=10)$ with a vernier caliper 
Tsuji et al. 9

126 (THS-30, Niigata Seiki Co., Japan) to the nearest $0.05 \mathrm{~mm}$. We also weighed dry seeds on

127 an electric balance (UX4200H, Shimadzu Co., Japan) to the nearest $0.01 \mathrm{mg}$. We

128 estimated seed volume based on the following formula suggested by Garber (1986):

129

$$
V=\pi R^{2}\left(L-\frac{2}{3} R\right)
$$

130 where $R=$ (seed width + height $) / 4$, and $L=$ seed length. The specific gravity of the seed

$131\left(\mathrm{mg} \cdot \mathrm{mm}^{-3}\right)$ was calculated as (dry seed weight/seed volume).

132 We inserted both plastic and real seeds into chunks of banana and fed them to the

133 monkeys. We adjusted the number of seeds inserted into the banana to total

134 approximately $400-500 \mathrm{~mm}^{3}$ to eliminate the effect of total seed volume on the passage

135 time (Table 1). Each animal was fed seed-loaded bananas once during the morning meal

136 (10:00). Single type of seeds was fed to a given animal for each experiment, and same

137 type of seeds was fed to all macaques on a given experiment. We visited the experimental

138 room at least every two hours from 6:00 to 18:00 to determine whether the monkeys had

139 defecated. Since we did not observe defecating behavior, the passage time was estimated

140 at two-hour intervals. Though we did not observe the monkeys during the night

141 (18:00-6:00), this would not affect the results because the monkeys rarely (only twice)

142 defecated during this time. Each fecal sample collected was washed and screened by a

143 sieve (mesh size, $0.5 \mathrm{~mm}$ ) to determine whether seeds were present. If we found seeds, 
144 the time of the sample collection and the number of seeds were recorded. We ended an

145 experimental session when no new seed was found in the feces within 24 hours from the

146 last seed appearance. We started the next experimental session after at least a one-day

147 interval from the previous experiment.

148 From the obtained data we calculated time of first appearance of a seed: transit time

149 (TT), time of last appearance of a seed (TLA), and mean retention time (MRT). The $M R T$

150 was calculated according to the following formula (Lambert, 2002):

151

$$
M R T=\sum_{i=1} m_{i} t_{i} / \sum_{i=1} m
$$

152 where $m_{i}=$ the number of seeds excreted at the $i$ th defecation at time $t_{i}(\mathrm{hr})$ after ingestion.

154 Statistical analyses

155 We tested the effects of the seed type (plastic and real) on the percentage of seed recovery

156 and on the three variables associated with passage time (TT, MRT, and TLA), and the

157 effects of individual macaque on the passage times. For these analyses, we calculated the

158 median instead of the mean and standard deviation, and employed Friedman's two-way

159 ANOVAs since our data were not normally distributed (tested by Shapiro-Wilk normality

160 test, $P<0.05)$. We tested correlations between the percentage of seed recovery and

161 physical dimensions of seeds, and correlations among the three passage time variables 
162 using Spearman's correlation analyses. Significance levels were set at 5\% for these 163 analyses. We examined the effects of the physical characteristics of seeds (dry weight,

164 volume, and specific gravity) on the passage time using the generalized linear models

165 (GLM). We assumed gamma distributions for the three variables associated with passage 166 time. Then the best model was determined by removing independent variables that did 167 not improve Akaike's information criterion (AIC) compared to that for the full model. All 168 data analyses were carried out using the statistical software $\mathrm{R}$ version 2.4.1 ( $\mathrm{R}$ 169 Development Core Team, 2006).

$171 \quad$ Results

172 Administration and recovery of seeds

173 The monkeys readily and immediately consumed the real and plastic seeds concealed in

174 chunks of banana. Spitting out was rarely observed for the real seeds $(n=5$, mean $\pm S D$

$175=2.8 \pm 6.4 \%$ of seeds in a banana (six types mean)), while for the plastic seeds

176 relatively many of the seeds were spat out $(29.0 \pm 17.6 \%$ of larger and $10.5 \pm 12.1 \%$

177 of smaller seeds) (Table 1).

178 Among eight feeding trials, the median of seed recovery percentage for the real 179 seeds per individual monkey was $35.5 \%$ (range, 24\%-78 \%). The median percentage of 
180 plastic seeds recovered was $81.5 \%$ (range, 65\%-86\%) (Table 1). The percentage of seed

181 recovery varied significantly among the real seed types (Friedman's two-way ANOVA,

$\left.182 \chi^{2}=18.94, d f=5, P<0.01\right)$, although none of the physical dimensions of the real seeds

183 correlated with the percentage of recovery (Spearman's correlation analyses, $d f=5$, dry

184 seed weight: $r_{s}=0.26, P=0.658$; seed volume: $r_{s}=0.03, P=1.000$; specific gravity of

185 seed: $\left.r_{s}=0.60, P=0.242\right)$.

186

187 Gut passage time and physical characteristics of seeds

188 The passage rates measured by TT, MRT, and TLA were 22-35 hr (Fig. 1a), 37-54 hr (Fig.

189 1b), and 53-109 hr (Fig. 1c), respectively. We treated the three passage time variables as

190 independent of each other because there were no correlations among them (Spearman's

191 correlation analyses, $d f=7, T T$ vs $M R T: r_{s}=0.68, P=0.062 ; T T$ vs $T L A: r_{s}=0.24, P=$

$1920.568 ; M R T$ vs $T L A: r_{s}=0.70, P=0.069$ ). Among these variables, $M R T$ (median: $44.7 \mathrm{hr}$ )

193 and TLA (median: $70.0 \mathrm{hr}$ ) differed significantly among the seed types (Friedman's

194 two-way ANOVA, $\left.d f=7, M R T: \chi^{2}=14.58, P=0.042 ; T L A: \chi^{2}=21.32, P=0.003\right) . T T$

195 (median: $24.0 \mathrm{hr}$ ), however, did not differ significantly among the seed types $\left(\chi^{2}=11.63\right.$,

$196 P=0.114)$. On the other hand, $M R T$ differed significantly among individual macaques

197 (Friedman's two-way ANOVA, $d f=4, \chi^{2}=11.66, P=0.020$ ), while $T T$ and $T L A$ did not 
$198\left(T T: \chi^{2}=1.60, P=0.809 ; T L A: \chi^{2}=8.94, P=0.062\right)$. When we omitted the plastic beads

199 from the analysis, only TLA differed significantly among the real seed types (Friedman's

200 two-way ANOVA, $d f=5, T T: \chi^{2}=8.43, P=0.634 ; M R T: \chi^{2}=6.91, P=0.243 ; T L A: \chi$

$\left.202^{2}=20.24, P=0.001\right)$. In this case, $T L A$ also differed significantly among individual

202 macaques (Friedman's two-way ANOVA, $d f=4, \chi^{2}=10.40, P=0.034$ ), while $T T$ and

$203 M R T \operatorname{did} \operatorname{not}\left(T T: \chi^{2}=2.48, P=0.648 ; M R T: \chi^{2}=8.48, P=0.076\right)$.

204 The GLM selected dry seed weight as a factor affecting $M R T$ (positive effect), and

205 specific gravity as a factor affecting TLA (positive effect) (Table 2). When we omitted the

206 plastic beads from the analysis of the TLA, the GLM again selected specific gravity as the 207 sole factor (positive) (Table 2).

209 Discussion

210 The median percentage of real seeds recovered per individual monkey was $36 \%$. This

211 result is probably due to the fact that the Japanese macaques act both as seed dispersers

212 and as seed predators (Yumoto et al., 1998; Otani and Shibata, 2000; Otani, 2003). Otani

213 (2003), for example, found some cracked seeds of relatively large-seeded species (e.g.,

214 Akebia trifoliata (mean cubic diameter: $3.6 \mathrm{~mm}$ ) and Berchemia racemosa $(3.2 \mathrm{~mm})$ )

215 with their intact seeds in macaque feces. Percent seed recovery was not significantly 
Tsuji et al. 14

216 correlated with dry seed weight, volume, or specific gravity. Kunz \& Linsenmair (2008a)

217 also reported the absence of a linear correlation between seed size and that of seed

218 damage in their study of olive baboons Papio anubis. It is possible that characteristics of

219 seeds, such as hardness or shape, may help to explain the low seed recovery rate of

220 several seed types reported in our study. Corlett \& Lucas (1990) reported that captive

221 studies exaggerate seed predation, and this might also be the case in our study. Seed

222 spitting is another handling behavior in cercopithecine monkeys, including macaques

223 (Corlett \& Lucas, 1990; Lucas \& Corlett, 1998). For Japanese macaques in our study,

224 however, spitting out of the seeds was rarely observed (3\%), though the plastic beads

225 were spat out more (29\%) (Table 1). Small seed size might contribute to the lower

226 percentage of seed spitting (Lucas \& Corlett, 1998).

227 Measurements of the transit time (TT) and the mean retention time $(M R T)$ in the

228 female Japanese macaques in our study (TT, 22-35 hr, MRT, 37-54 hr) (Fig. 1a, 1b) were

229 similar to those found in previous studies of cercopithecine monkeys $(T T, 20 \mathrm{hr}$ for

230 Cercopithecus ascanius, $17 \mathrm{hr}$ for C. mitis, $21 \mathrm{hr}$ for C. neglectus (Lambert, 2002), and 23

$231 \mathrm{hr}$ for Lophocebus albigena (Maisels, 1993); MRT, $27 \mathrm{hr}$ for C. ascanius, $25 \mathrm{hr}$ for $C$.

232 mitis, $34 \mathrm{hr}$ for C. neglectus (Lambert, 2002), $38 \mathrm{hr}$ for L. albigena (Maisels, 1993), and

$23339 \mathrm{hr}$ for Macaca fuscata (Otani, 2004)). In general, seed passage time of Old World 
Tsuji et al. 15

234 monkeys is considerably longer than that reported for most species of New World

235 monkeys (Lambert, 1998; Chapman \& Russo, 2007). Further, when the effects of body

236 size were removed, the passage time of Old World monkeys also is significantly greater

237 than that of apes (Lambert, 2002). Relatively long retention time is one of physiological

238 traits of cercopithecine monkeys, including Japanese macaques, and this might facilitate

239 more efficient consumption of a high fiber non-fruit diet and parts while maintaining a

240 greater capacity to detoxify secondary metabolites (Lambert, 2002).

241 Among the three variables of the passage time of seeds treated in this study, $T T$ did

242 not differ among seed types used in the feeding experiments and among individual

243 macaques $(P>0.05)$. In contrast, $M R T$ and $T L A$ of a seed differed significantly among

244 seed types, and, for the latter, among individuals $(P<0.05)$ : dry seed weight showed a

245 positive effect on $M R T$, while specific gravity of seeds showed a positive effect on TLA

246 (Table 2). Furthermore, it is noteworthy that the positive effect of the specific gravity on

247 TLA was irrelevant to the plastic beads, which had a quite high specific gravity. Our study

248 is the first to demonstrate the effect of the physical characteristics of seeds on the passage

249 time in cercopithecine monkeys, though we should consider the effect of the individual

250 variation in the passage times, too. Our results imply that 1) (at least) seeds with higher

251 specific gravity and (or) heavier seeds will be dispersed farther from the parent plants, 
Tsuji et al. 16

252 and 2) (at least) seeds with lower specific gravity and (or) the lighter seeds will be

253 dispersed nearer the parent. Interestingly, the effect of specific gravity of seeds on the

254 passage time was opposite to Garbers' (1986) result which suggested that the specific

255 gravity of seeds was negatively correlated with passage time through the gut of two

256 callitrichid species. The difference in the effect of specific gravity of seeds between the

257 macaques and tamarins would be attributed to the difference in relative gut volume and

258 digestive systems (Strier, 2000; Lambert, 1998), or due to the difference in metabolism

259 between them.

260 On the basis of present results, testing the relationship between dispersal distribution

261 of seeds and their performance (e.g., germination and growth of seedling) in the field is

262 needed to draw conclusions about the adaptive significance of the effects of physical

263 characteristics of the seeds on gut passage time.

265 Acknowledgements

266 We thank the staffs of the Center for Human Evolution Modeling Research of the Primate

267 Research Institute, Kyoto University for their cooperation in our feeding experiments,

268 and Dr. P. A. Garber and the staff of the Department of Ecology and Social Behavior of

269 the Primate Research Institute, Kyoto University, for their constructive comments. 


\section{$271 \quad$ References}

272 Augspurger, C.K. (1984). Seedling survival of tropical tree species: interactions of 273 dispersal distance, light-gaps, and pathogens. Ecology 65, 1705-1712.

274 Chapman, C.A. \& Chapman, L.J. (1996). Frugivory and the fate of dispersed and 275 non-dispersed seeds of six African tree species. J. Trop. Ecol. 12, 491-504.

276 Chapman, C.A. \& Russo, S.E. (2007). Primate seed dispersal. In Primate in Perspective:

277 510-525. Campbell, C.J., Fuentes, A., MacKinnon, K.C., Pager, M. \& Boarder, S.K.

278 (Eds.). Oxford: Oxford University Press.

279 Corlett, R.T. \& Lucas, P.W. (1990). Alternative seed-handling strategies in primates: seed-spitting by long-tailed macaques (Macaca fascicularis). Oecologia $\mathbf{8 2}$, 166-171.

Direnfeld, E.S., Koontz, F.W. \& Goldstein, R.S. (1992). Feed intake, digestion and passage of the proboscis monkey (Nasalis larvatus) in captivity. Primates 33, $399-405$

Garber, P.A. (1986). The ecology of seed dispersal in two species of Callitrichidae primates (Saguinus mystax and Saguinus fuscicollis). Am. J. Primatol. 10, 155-170.

287 Gardener, C.J., McIvor, J.G. \& Jansen, A. (1993). Passage of legume and grass seeds 
288

289

290

291

292

293

294

295

296

297

298

299

300

301

302

303

304

305

through the digestive tract of cattle and their survival in feces. J. Appl. Ecol. 30, 63-74.

Graae, B.J., Pagh, S. \& Bruun, H.H. (2004). An experimental evaluation of the arctic fox (Alopex lagopus) as a seed disperser. Arc. Antarc. Alpine. Res. 36, 468-473.

Julliot, C. (1996). Seed dispersal by red howling monkeys (Alouatta seniculus) in the tropical rain forest of French Guiana. Int. J. Primatol. 17, 239-258.

Kaplin, B.A. \& Moermond, T.C. (1998). Variation in seed handling by two species of forest monkeys in Rwanda. Am. J. Primatol. 45, 83-101.

Kunz, B.K. \& Linsenmair, K.E. (2008a). The role of the olive baboon (Papio anubis, Cercopithecidae) as seed disperser in a savanna-forest mosaic of West Africa. $J$. Trop. Ecol. 24, 235-246.

Kunz, B.K. \& Linsenmair, K.E. (2008b). Seed size selection by olive baboons. Primates 49, 239-245.

Lambert, J.E. (1998). Primate digestion: interactions among anatomy, physiology, and feeding ecology. Evol. Anthropol. 7, 8-20.

Lambert, J.E. (2001). Red-tailed guenons (Cercopithecus ascanius) and Strychnos mitis: evidence for plant benefits beyond seed dispersal. Int. J. Primatol. 22, 189-201.

Lambert, J.E. (2002). Digestive retention times in forest guenons (Cercopithecus spp.) 

with reference to chimpanzees (Pan troglodytes). Int. J. Primatol. 23, 1169-1185.

Leavy, D.J. \& Grajal, A. (1991). Evolutionary implications of fruit-processing limitation in cedar wax wings. Am. Nat. 138, 171-189.

309

Link, A. \& Di Fiore, A. (2006). Seed dispersal by spider monkeys and its importance in the maintenance of Neotropical rain-forest diversity. J. Trop. Ecol. 22, 235-246.

Lucas, P.W. \& Corlett, R.T. (1998). Seed dispersal by long-tailed macaques. Am. J. Primatol. 45, 29-44.

313 Maisels, F. (1993). Gut passage rate in guenons and mangabeys: another indicator of a flexible feeding niche? Folia Primatol. 61, 35-37.

Martins, M.M. (2006). Comparative seed dispersal effectiveness of sympatric Alouatta guariba and Brachyteles arachnoids in Southeastern Brazil. Biotropica 38, 57-63.

Mori, A. (1979). An experiment on the relation between the feeding speed and the caloric intake through leaf eating in Japanese monkeys. Primates 20, 185-195.

319 Nakagawa, N., Iwamoto, T., Yokota, N. \& Soumah, A.G. (1996). Inter-regional and 320 inter-seasonal variation of food quality in Japanese macaques: with reference to the 321 constraints of digestive volume and feeding time. In Evolution and Ecology of 322 Macaque species: 207-234. Fa, J.E. \& Lindberg, D.G. (Eds.). Cambridge: $323 \quad$ Cambridge University Press. 
324 Otani, T. \& Shibata, E. (2000). Seed dispersal and predation by Yakushima macaques, 325 Macaca fuscata yakui, in a warm temperate forest of Yakushima Island, southern $326 \quad$ Japan. Ecol. Res. 15, 133-144.

327 Otani, T. (2003). Seed dispersal and predation of fleshy-fruited plants by Japanese 328 macaques in the cool temperate zone of northern Japan. Mamm Study 28, 153-156.

329 Otani, T. (2004). Effects of macaque ingestion on seed destruction and germination of a 330 fleshy-fruited tree, Eurya emarginata. Ecol. Res. 19, 495-501.

331 Pollux, B.J.A., Ouborg, N.J., van Groenendael, J.M. \& Klaassen, M. (2007). Consequences of intraspecific seed-size variation in Sparganium emersum for dispersal by fish. Func. Ecol. 21, 1084-1091.

334 Raemakers, J. (1980). Causes of variation in the distance traveled daily by gibbons. Folia $335 \quad$ Primatol. 23, 46-60.

336 R Development Core Team. (2006). R: A language and environment for statistical computing. Version 2.4.1. Vienna, Austria, R Foundation for Statistical Computing.

338 Remis, M.J. (2000). Initial studies on the contributions of body size and gastrointestinal 339 passage rates to dietary flexibility among gorillas. Am. J. Phys. Anthropol. 112, 340 171-180.

341 Schwarm, A., Ortmann, S., Wolf, C., Streich, W.J. \& Clauss, M. (2008). Excretion 
342

343

344

345

346

347

348

349

350

351

352

353

354

355

356

357

358

359

patterns of fluid and different sized particle passage markers in banteng (Bos javanicus) and pygmy hippopotamus (Hexaprotodon liberiensis): two functionally different foregut fermenters. Comp. Biochem. Physiol. A. 150, 32-39.

Strier, K.B. (2000). Primate Behavioral Ecology. 1st edn. Boston: Allyn \& Bacon.

Traveset, A. (1998). Effect of seed passage through vertebrate frugivores' guts on germination: a review. Persp. Plant Ecol. Evol. Syst. 1/2, 151-190.

Varela, O. \& Bucher, E.H. (2006). Passage time, viability, and germination of seeds ingested by foxes. J. Arid. Environ. 67, 566-578.

Wilson, M.F. (1989). Gut retention times of experimental pseudoseeds by emus. Biotropica 21, 210-213.

Wotton, D.M., Clout, M.N. \& Kelly, D. (2008). Seed retention times in the New Zealand pigeon (Hemiphaga novaezeelandiae novaeseelandiae). NZ. J. Ecol. 32, 1-6.

Yumoto, T., Noma, N. \& Maruhashi, T. (1998). Cheek-pouch dispersal of seeds by Japanese monkeys (Macaca fuscata yakui) on Yakushima Island, Japan. Primates 39, 325-338.

Yumoto, T., Kimura, K. \& Nishimura, A. (1999). Estimation of the retention times and distances of seed dispersed by two monkey species, Alouatta seniculus and Lagothrix lagotricha, in a Colombian forest. Ecol. Res. 14, 179-191. 


\section{FIGURE LEGENDS}

361 Figure 1. Relationships between the seed type (eight types) and the passage time

362 variables: a) transit time $(T T)$, b) mean retention time $(M R T)$, and c) time of last

363 appearance of a seed (TLA). Filled circles show mean values and bars show standard

364 deviations (SD).

365

366 The English in this document has been checked by at least two professional editors,

367 both native speakers of English. For a certificate, see:

368 http://www.textcheck.com/certificate/U4tGOG 


\begin{tabular}{|c|c|c|c|c|c|c|c|c|c|c|c|c|c|c|c|c|c|c|c|c|}
\hline \multirow{4}{*}{$\begin{array}{l}\text { Seed type } \\
\text { Small beads }\end{array}$} & \multicolumn{9}{|c|}{ Physical characteristics of seeds } & \multicolumn{2}{|c|}{ Dose } & \multicolumn{9}{|c|}{ Fate of seeds (\# of seeds, mean \pm SD) } \\
\hline & \multicolumn{6}{|c|}{ Size $(\mathrm{mm}$, mean $\pm \mathrm{SD})$} & \multirow{2}{*}{$\begin{array}{c}\text { Dry weight } \\
\text { (mg, mean } \pm \mathrm{SD})\end{array}$} & \multirow{3}{*}{$\begin{array}{c}\begin{array}{c}\text { Volume } \\
\left(\mathrm{mm}^{3}\right)\end{array} \\
3.75\end{array}$} & \multirow{3}{*}{$\begin{array}{c}\begin{array}{c}\text { Specific } \\
\left.\text { (ravity }{ }^{\mathrm{b}}\right) \\
\left(\mathrm{mg} \cdot \mathrm{mm}^{-3}\right)\end{array} \\
3.33\end{array}$} & \multirow{3}{*}{$\begin{array}{r}\begin{array}{c}\text { No. of } \\
\text { seeds in a } \\
\text { banana }\end{array} \\
110\end{array}$} & \multirow{3}{*}{$\begin{array}{c}\begin{array}{c}\text { Total } \\
\text { volume } \\
\left(\mathrm{mm}^{3}\right)\end{array} \\
412.5\end{array}$} & \multirow{2}{*}{\multicolumn{3}{|c|}{ Defecated }} & \multirow{2}{*}{\multicolumn{3}{|c|}{ Spitted out }} & \multirow{2}{*}{\multicolumn{3}{|c|}{ Destructed }} \\
\hline & \multicolumn{2}{|c|}{ Length } & \multicolumn{2}{|c|}{ Width } & \multicolumn{2}{|c|}{ Height } & & & & & & & & & & & & & & \\
\hline & 2.10 & \pm 0.09 & 2.12 & \pm 0.09 & 1.45 & \pm 0.12 & $9.60 \pm 0.46$ & & & & & 94.6 & \pm & 18.2 & 11.6 & \pm & 13.3 & 4.0 & \pm & 5.2 \\
\hline Large beads & 2.84 & \pm 0.11 & 2.76 & \pm 0.14 & 1.88 & \pm 0.13 & $25.70 \pm 6.58$ & 8.72 & 2.95 & 40 & 348.8 & 25.8 & \pm & 11.1 & 11.6 & \pm & 7.1 & 2.6 & \pm & 4.7 \\
\hline Radish & 4.14 & \pm 0.21 & 3.26 & \pm 0.21 & 2.53 & \pm 0.28 & $18.20 \pm 2.78$ & 20.84 & 0.87 & 20 & 416.8 & 7.2 & \pm & 3.0 & 0.0 & \pm & 0.0 & 12.8 & \pm & 3.0 \\
\hline Eggplant & 3.45 & \pm 0.17 & 2.89 & \pm 0.27 & 0.93 & \pm 0.12 & $4.04 \pm 0.47$ & 8.03 & 0.50 & 50 & 401.5 & 39.0 & \pm & 6.9 & 0.2 & \pm & 0.5 & 10.8 & \pm & 6.8 \\
\hline Spinach & 3.84 & \pm 0.40 & 3.23 & \pm 0.29 & 2.31 & \pm 0.30 & $11.35 \pm 1.97$ & 17.58 & 0.65 & 25 & 439.5 & 6.0 & \pm & 2.9 & 0.4 & \pm & 0.6 & 18.6 & \pm & 2.5 \\
\hline Melon & 6.24 & \pm 0.59 & 3.22 & \pm 0.16 & 0.99 & \pm 0.15 & $8.67^{\mathrm{c})}$ & 19.21 & 0.45 & 20 & 384.2 & 9.4 & \pm & 3.9 & 1.0 & \pm & 2.2 & 9.6 & \pm & 3.8 \\
\hline Potherb Mustard & 1.62 & \pm 0.18 & 1.43 & \pm 0.12 & 1.43 & \pm 0.12 & $1.74 \quad \pm 0.35$ & 1.83 & 0.95 & 230 & 420.9 & 56.0 & \pm & 13.4 & 12.2 & \pm & 27.3 & 161.8 & \pm & 40.3 \\
\hline Bermuda grass & 1.38 & \pm 0.09 & 0.71 & \pm 0.11 & 0.68 & \pm 0.11 & $0.19^{\mathrm{d})} \pm 0.02$ & 0.44 & 0.44 & 1300 & 572.0 & 538.0 & \pm & 247.9 & 0.0 & \pm & 0.0 & 762.0 & \pm & 247.9 \\
\hline
\end{tabular}

The sample number of seed measurements was ten for each species.

a) Seed volume was calculated by using the following formula: $V=\pi R^{2}(L-2 / 3 R) ; V=$ volume, $R=$ (width + height) $/ 4, L=$ length.

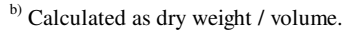

${ }^{c}$ Dry seed weight was measured only once.

${ }^{\text {d) }}$ Dry seed weight was measured five times. 
Table 2. Selected physical characteristics of seeds affecting passage time variables by GLM: mean retention time (MRT) and time of last appearance (TLA).

\begin{tabular}{|c|c|c|c|}
\hline \multirow[b]{3}{*}{ Independent variable } & \multicolumn{3}{|c|}{ Dependent variable } \\
\hline & $M R T$ & $T L A$ & $T L A$ (without beads) \\
\hline & Estimate $\pm \mathrm{SE}$ & Estimate $\pm \mathrm{SE}$ & Estimate $\pm \mathrm{SE}$ \\
\hline Intercept & $3.736 \pm 0.062 * * *$ & $4.071 \pm 0.072 * * *$ & $3.915 \pm 0.199 * * *$ \\
\hline Dry weight & $0.011 \pm 0.005$ & - & - \\
\hline Volume & - & - & - \\
\hline Specific gravity & - & $\pm 0.043 * *$ & $0.416 \pm 0.294$ \\
\hline
\end{tabular}

$*: P<0.05, * *: P<0.01, * * *: P<0.001$ 
1

2

3

4

5

6

7

8

9

10

11

12

13

14

15

16

17

18

19

20

21

22

23

24

25

26

27

28

29

30

31

32

33

34

35

36

37

38

39

40

41

42

43

44

45

46

47

48

49

50

51

52

53

54

55

56

57

58

59

60

Tsuji et al. Figure 1
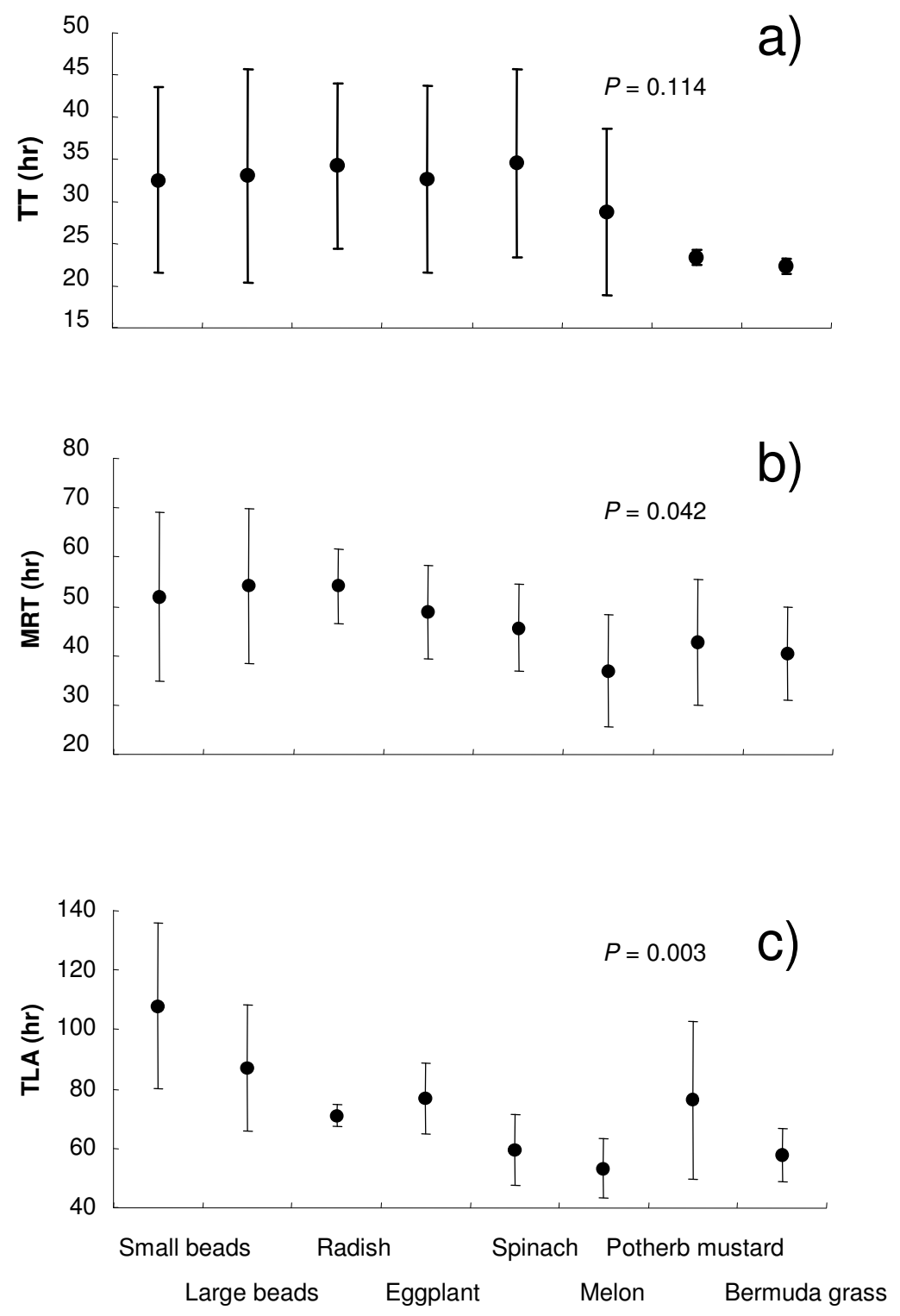

Seed type 